\title{
Structure-cation complexation relationships for ortho-, meta-, and para-substituted bis(oxymethylcrown)benzenes and $\alpha, \alpha^{\prime}$-xylenes
}

\author{
David A. Babb, Bronislaw P. Czech, and Richard A. Bartsch* \\ Department of Chemistry and Biochemistry, Texas Tech University, Lubbock, Texas 79409 \\ E-mail: Richard.Bartsch@ttu.edu
}

Dedicated to Professor Henry J. Shine on the occasion of his $80^{\text {th }}$ birthday

(received 24 Jun 03; accepted 08 Jan 04; published on the web 16 Jan 04)

\begin{abstract}
New bis(crown ether) compounds are synthesized by attaching two (hydroxymethyl)crown ether units to a benzene or $\alpha, \alpha^{\prime}$-xylene framework. Bis(15-crown-5) polyether substitution patterns are varied from ortho to meta to para. ortho-Bis(18-crown-6) polyethers are prepared together with mono(crown ether) analogs, as well as ortho-bis(12-crown-4) polyethers. Complexation abilities of these compounds for alkali metal cations are evaluated by picrate extraction allowing the influence of structural modifications in the ligands on extraction constants $\left(\mathrm{K}_{\mathrm{ex}}\right)$ and association constants $\left(\mathrm{K}_{\mathrm{a}}\right)$ for alkali metal cations to be assessed.
\end{abstract}

Keywords: Host-guest chemistry, bis(crown ethers), alkali metal cations, complexation, picrate extraction

\section{Introduction}

Early in the investigation of crown ether-cation interactions it was determined that crown ethers can form 2:1 (host:guest) "sandwich" complexes with cations that are too large to fit into the macrocyclic cavity. ${ }^{1-5}$ This led to the synthesis of new compounds in which two or more crown ether units were covalently linked in a fashion to promote formation of intramolecular 2:1 (crown ether:cation) complexes. ${ }^{6}$ Subsequently, bis(crown ethers) have found a variety of applications and their enhanced binding properties and greater selectivities than mono(crown ethers) have been well-established. ${ }^{7-13}$

We now report the results of a systematic study of structural variations in bis(crown ethers) formed by attaching two (hydroxymethyl)crown ether units to a benzene or $\alpha, \alpha$ '-xylene framework. The influence of these structural variations (crown ether ring size and length of the spacer between the crown ether ring and the central benzene ring) upon alkali metal cation complexation are assessed by picrate extraction. 


\section{Results and Discussion}

\section{Synthesis}

Bis[(oxymethyl)crown] ethers 1-3, 7, and $\mathbf{8}$ and the analogous mono(oxymethyl)crown ether 12 were prepared by reaction of the appropriate dihydroxybenzene (or phenol for 12) with $\mathrm{NaH}$ or $\mathrm{KH}$ in THF and then with the appropriate (tosyloxymethyl)crown ether. Refluxing the mixture for 48 hours and workup with purification of the crude product by column chromatography gave these polyether ligands as oils in $65-85 \%$ yields.

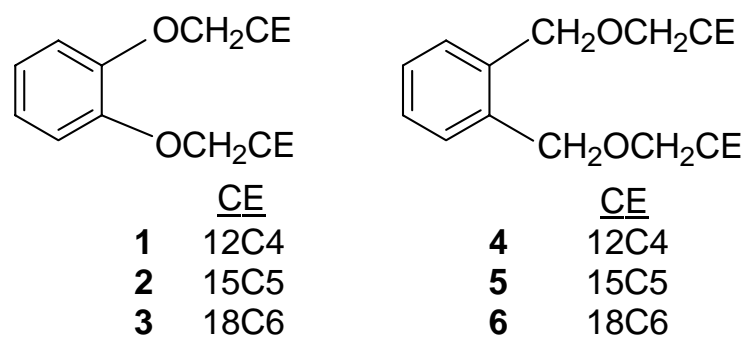<smiles>FC(F)COCc1cccc(COCC(F)(F)F)c1</smiles><smiles></smiles><smiles>FC(F)(F)COc1cccc(OCc2ccccc2)c1</smiles>

$7 \quad C E=15 C 5 \quad 8$<smiles>Oc1ccc(OCC(F)(F)F)cc1</smiles>$$
8
$$<smiles>COCc1cccc(COCC(F)F)c1OC</smiles><smiles></smiles>

$9 \quad \mathrm{CE}=15 \mathrm{C} 5$

10

$\mathrm{CE}=15 \mathrm{C} 511$

$\alpha, \alpha^{\prime}$-Bis-[(oxymethyl)crown] xylenes 4-6 and 9-11 were synthesized by reaction of the appropriate (hydroxymethyl)crown ether with $\mathrm{NaH}$ in THF and then with the appropriate $\alpha, \alpha^{\prime}-$ dibromoxylene. Refluxing the mixture overnight and workup with purification of the crude product by column chromatography produced these polyether ligands as oils in 50-77\% yields.

For bis(crown ethers) 1-3 and 4-6, the systematic structural variation is changing the crown ether ring size from 12-crown-4 to 15-crown-5 to 18-crown-6. For the two series of bis(crown ethers) $2,7,8$ and 5, 9, 10, there is a common 15-crown-5 ring size and the attachment of the two crown ether-containing substituents to the central benzene unit is varied from ortho to meta to para. The series of bis(crown ethers) 1-3, 7, 8 differs from the series 4-6, 9, 11 in the former has a $-\mathrm{CH}_{2} \mathrm{O}$ - linkage between the crown ether ring and benzene ring and for the latter this linkage is $-\mathrm{CH}_{2} \mathrm{OCH}_{2-}$. For meta-bis(15-crown-5) ethers 9 and 11, the hydrogen on the benzene ring between the two crown ether-containing substituents in the former is replaced by a methoxy group in the latter.

The alkali metal ion complexing properties of bis(crown ether) ligands 1-11 and their mono(crown ether) analogs 12 and $\mathbf{1 3}$ were evaluated by alkali metal picrate extractions from 
aqueous solutions into deuteriochloroform. Extraction constants $\left(\mathrm{K}_{\mathrm{ex}}\right)^{14}$ and association constants $\left(\mathrm{K}_{\mathrm{a}}\right)^{15}$ were calculated by reported procedures. The stoichiometry of each extraction complex was ascertained from the position of the absorption maximum for the picrate anion in the organic phase after dilution with THF. ${ }^{5}$ A maximum in the range of $375-385 \mathrm{~nm}$ indicates a separated ion pair and is consistent with formation of a sandwich complex involving two crown ether units and one metal ion. A maximum in the range of $355-365 \mathrm{~nm}$ reveals a tight ion pair and association of the alkali metal cation with a single polyether ring. Hereafter, we will refer to the former as a 2:1 complex [even though both crown ether rings are provided by a bis(crown ether) ligand] and the former as a 1:1 complex.

\section{Bis(12-crown-4) hosts 1 and 4}

Picrate extraction data and association constants $\left(\mathrm{K}_{\mathrm{a}}\right)$ for complexation of alkali metal picrates by bis(crown ethers) 1 and $\mathbf{4}$, which each have two 12-crown-4 rings, are presented in Table 1.

Table 1. Alkali metal picrate extraction from aqueous solution into deuteriochloroform by bis(12-crown-4) ligands 1 and 4

\begin{tabular}{cccccc}
\hline Ligand & $\mathrm{M}^{+}$ & Percent extraction & $\log \mathrm{K}_{\mathrm{ex}}$ & $\log \mathrm{K}_{\mathrm{a}}$ & $\lambda_{\max }(\mathrm{nm})$ \\
\hline $\mathbf{1}$ & $\mathrm{Li}$ & 0.4 & 1.02 & 3.86 & 383 \\
& $\mathrm{Na}$ & 3.2 & 1.89 & 4.65 & 367 \\
& $\mathrm{~K}$ & 1.2 & 1.42 & 4.01 & 378 \\
& $\mathrm{Rb}$ & 1.0 & 1.39 & 3.73 & 379 \\
& $\mathrm{Cs}$ & $\mathrm{ND}^{\mathrm{b}}$ & ----- & ----- & ---- \\
\hline \multirow{4}{*}{} & $\mathrm{Li}$ & 0.8 & 1.25 & 4.10 & 380 \\
& $\mathrm{Na}$ & 5.6 & 2.16 & 4.92 & 365 \\
& $\mathrm{~K}$ & 1.3 & 1.44 & 4.03 & 380 \\
& $\mathrm{Rb}$ & 0.8 & 1.25 & 3.58 & 380 \\
& $\mathrm{Cs}^{\mathrm{a}}$ & 0.3 & 1.71 & 3.97 & 380 \\
\hline
\end{tabular}

${ }^{\mathrm{a}}$ Cesium picrate extractions were conducted using a different concentration. ${ }^{\mathrm{b}}$ Not detected.

Complexation of $\mathrm{Li}^{+}$by 12-crown-4 hosts has been the subject of earlier investigations. ${ }^{16-18}$ Although at least one X-ray crystal structure has appeared showing $\mathrm{Li}^{+}$in a 12-crown-4 sandwich complex, ${ }^{19}$ this is probably a rare occurrence, especially in solution. The $\lambda_{\max }$ values observed for extractions of lithium picrate by bis(crown ethers) 1 and $\mathbf{4}$ indicate separated ion pairs. However, it is postulated that this is the result of water in the $\mathrm{Li}^{+}$solvation sphere of the extraction complex, rather than formation of a sandwich complex.

Although the association constants for all of the alkali metal cations are small, both bis(12crown-4) ligands 1 and 4 exhibit their greatest extraction capacity for $\mathrm{Na}^{+}$. The $\lambda_{\max }$ values for sodium picrate extraction are intermediate between those for tight and separated ion pairs indicating that the extraction complexes are a mixture of $\mathrm{Na}^{+}$associated with one and both crown 
ether rings in the bis(crown ether) host. The association constant for complexation of sodium picrate is higher for $\mathbf{4}$, which has a longer spacer between the polyether ring and the central benzene ring, than for 1 . The $\lambda_{\max }$ values for complexes formed in potassium, rubidium, and cesium picrate extractions are consistent with 2:1 complexes.

The association constants in deuteriochloroform decrease in the order $\mathrm{Na}^{+}>\mathrm{K}^{+}>\mathrm{Li}^{+}>\mathrm{Rb}^{+}>\mathrm{Cs}^{+}$ for $\mathbf{1}$ and $\mathrm{Na}^{+}>\mathrm{Li}^{+}>\mathrm{K}^{+}, \mathrm{Cs}^{+}>\mathrm{Rb}^{+}$for $\mathbf{4}$.

\section{Bis(15-crown-5) hosts}

The influence of two different structural modifications were probed with bis(15-crown-5) ethers: i) attachment of the two crown ether-containing substituents ortho, meta, and para on the central benzene ring; and, ii) changing the length of the spacer between the crown ether unit and the central benzene ring.

\section{Bis(oxymethyl-15-crown-5)benzenes 2, 7, and 8}

Picrate extraction data and association constants $\left(\mathrm{K}_{\mathrm{a}}\right)$ for complexation of alkali metal picrates by bis(crown ethers) 2, 7, and 8, which each have two $-\mathrm{OCH}_{2}(15$-crown-5) substituents, are presented in Table 2 .

Table 2. Alkali metal picrate extraction from aqueous solution into deuteriochloroform by bis(15-crown-5) ligands $\mathbf{2}, \mathbf{7}$, and $\mathbf{8}$

\begin{tabular}{cccccc}
\hline Ligand & $\mathrm{M}^{+}$ & Percent extraction & $\log$ & $\log \mathrm{K}_{\mathrm{a}}$ & $\lambda_{\max }(\mathrm{nm})$ \\
& & & $\mathrm{K}_{\mathrm{ex}}$ & & \\
\hline $\mathbf{2}$ & $\mathrm{Li}$ & 2.2 & 1.73 & 4.58 & 358 \\
& $\mathrm{Na}$ & 50.2 & 3.76 & 6.54 & 354 \\
& $\mathrm{~K}$ & 62.4 & 4.11 & 6.76 & 380 \\
& $\mathrm{Rb}$ & 43.4 & 3.94 & 5.92 & 380 \\
& $\mathrm{Cs}^{\mathrm{a}}$ & 3.2 & 2.94 & 5.16 & 380 \\
\hline $\mathbf{7}$ & $\mathrm{Li}$ & 1.3 & 1.50 & 4.34 & 355 \\
& $\mathrm{Na}$ & 56.6 & 3.97 & 6.72 & ---- \\
& $\mathrm{K}^{\mathrm{b}}$ & 41.6 & 3.53 & 6.13 & ---- \\
& $\mathrm{Rb}^{\mathrm{b}}$ & 39.0 & 3.46 & 5.80 & 355 \\
& $\mathrm{Cs}^{\mathrm{a}}$ & 1.3 & 2.48 & 4.72 & 353 \\
\hline $\mathbf{8}$ & $\mathrm{Li}^{\mathrm{b}}$ & 1.2 & 1.48 & 4.30 & 353 \\
& $\mathrm{Na}^{\mathrm{b}}$ & 52.6 & 3.85 & 6.61 & 351 \\
& $\mathrm{~K}^{\mathrm{b}}$ & 40.6 & 3.51 & 6.10 & 354 \\
& $\mathrm{Rb}^{\mathrm{b}}$ & 44.2 & 3.62 & 5.95 & 355 \\
& $\mathrm{Cs}^{\mathrm{a}, \mathrm{b}}$ & 3.5 & 2.95 & 5.21 & 357 \\
& & & & & \\
\hline
\end{tabular}


${ }^{a}$ Cesium picrate extractions were conducted using a different concentration. ${ }^{b}$ Calculated from aqueous phase absorbance readings (see Experimental Section).

Extractions of $\mathrm{Li}^{+}$and $\mathrm{Cs}^{+}$were uniformly inefficient throughout the series. Association constants for complexation of sodium picrate by $\mathbf{2 ,} \mathbf{7}$, and $\mathbf{8}$ are high and show little variation as the attachment of the crown ether-containing substitutents is varied from ortho to meta to para. The $\lambda_{\max }$ values are consistent with $1: 1$ complexation of $\mathrm{Na}^{+}$. On the other hand, the $\lambda_{\max }$ values reveal 2:1 complexation with the ortho-substituted ligand 2 and $\mathrm{K}^{+}$, as well as $\mathrm{Rb}^{+}$and $\mathrm{Cs}^{+}$. The association constants for complexation of alkali metal picrates by ligand $\mathbf{2}$ decrease in the order of $\mathrm{K}^{+}>\mathrm{Na}^{+}>\mathrm{Rb}^{+}>\mathrm{Cs}^{+}>\mathrm{Li}^{+}$. The meta-substituted isomer 7 formed a precipitate when the deuteriochloroform solution obtained by extraction of the aqueous potassium picrate solution was diluted with THF, rendering determination of the stoichiometry by UV-visible absorbance impossible (see Experimental Section). However, the 1:1 complex stoichiometry evident for $\mathrm{K}^{+}$ with the para-substituted isomer $\mathbf{8}$ and the similarity of association constants for complexation of $\mathrm{K}^{+}$with 7 and 8 strongly suggests formation of a 1:1 complex for 7 with $\mathrm{K}^{+}$as well. The $\lambda_{\max }$ values for complexes of $\mathrm{Rb}^{+}$and $\mathrm{Cs}^{+}$with $\mathbf{7}$ and $\mathbf{8}$ are also consistent with 1:1 complexation.

Association constants for complexation of alkali metal picrates by the meta- and parasubstituted isomers 7 and $\mathbf{8}$, respectively, decrease in the order $\mathrm{Na}^{+}>\mathrm{K}^{+}>\mathrm{Rb}^{+}>\mathrm{Cs}^{+}>\mathrm{Li}^{+}$, which is a reversal of the relative positions for $\mathrm{Na}^{+}$and $\mathrm{K}^{+}$in the ordering observed for the orthosubstituted isomer 2 . The enhanced complexation of $\mathrm{K}^{+}$by $\mathbf{2}$ is clearly evident from the graphical presentation of the association constant data for isomers 2, 7, and $\mathbf{8}$ in Figure 1.

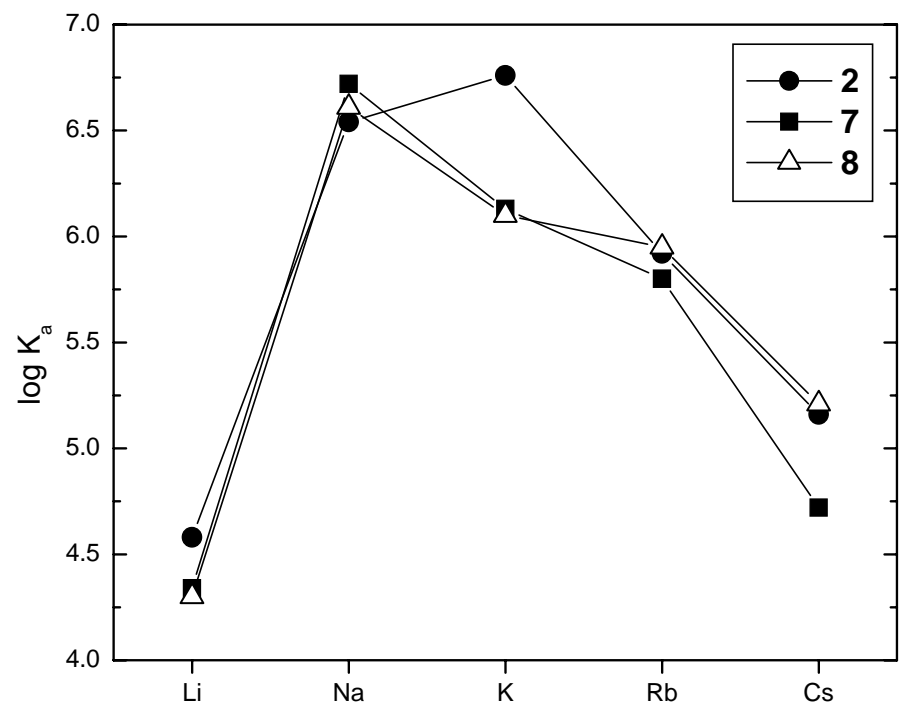


Figure 1. Association constants for complexation of alkali metal picrates by bis(15-crown-5) compounds 2, 7, and $\mathbf{8}$ in deuteriochloroform.

\section{$\alpha, \alpha^{\prime}$-Bis(oxymethyl-15-crown-5)xylenes 5 and 9-11}

Picrate extraction data and association constants $\left(\mathrm{K}_{\mathrm{a}}\right)$ for complexation of alkali metal picrates by bis(crown ethers) 5, 9, and 10, which each have two $-\mathrm{CH}_{2} \mathrm{OCH}_{2}(15$-crown-5) substituents, are presented in Table 3. For 5, 9, and 10, the structural variation is attachment of the two crown ether-containing substituents ortho, meta, and para, respectively on the central benzene ring.

Table 3. Alkali metal picrate extraction from aqueous solution into deuteriochloroform by bis(15-crown-5) ligands 5, 9, 10 and 11

\begin{tabular}{cccccc}
\hline Ligand & $\mathrm{M}^{+}$ & Percent extraction & $\log \mathrm{K}_{\mathrm{ex}}$ & $\log \mathrm{K}_{\mathrm{a}}$ & $\lambda_{\max }(\mathrm{nm})$ \\
\hline $\mathbf{5}$ & $\mathrm{Li}$ & 2.8 & 1.83 & 4.67 & 356 \\
& $\mathrm{Na}$ & 58.8 & 4.00 & 6.80 & 354 \\
& $\mathrm{~K}$ & 66.4 & 4.22 & 6.88 & 379 \\
& $\mathrm{Rb}$ & 58.8 & 4.04 & 6.38 & 379 \\
& $\mathrm{Cs}^{\mathrm{a}}$ & 2.5 & 2.84 & 5.04 & 363 \\
\hline $\mathbf{9}$ & $\mathrm{Li}$ & 2.3 & 1.73 & 4.58 & 356 \\
& $\mathrm{Na}$ & 57.0 & 3.99 & 6.74 & 354 \\
& $\mathrm{~K}$ & 59.6 & 4.03 & 6.66 & 380 \\
& $\mathrm{Rb}^{\mathrm{b}}$ & 53.6 & 3.88 & 6.22 & 380 \\
& $\mathrm{Cs}^{\mathrm{a}}$ & 3.9 & 3.05 & 5.28 & 367 \\
\hline $\mathbf{1 0}$ & $\mathrm{Li}$ & 1.6 & 1.59 & 4.43 & 355 \\
& $\mathrm{Na}$ & 57.6 & 4.04 & 6.76 & 352 \\
& $\mathrm{~K}^{\mathrm{b}}$ & 50.0 & 3.78 & 6.37 & 357 \\
& $\mathrm{Rb}$ & 26.4 & 3.11 & 5.43 & 359 \\
& $\mathrm{Cs}^{\mathrm{a}, \mathrm{b}}$ & 5.0 & 3.16 & 5.42 & 360 \\
\hline $\mathbf{1 1}$ & $\mathrm{Li}$ & 14.3 & 2.67 & 5.52 & 350 \\
& $\mathrm{Na}$ & 53.0 & 3.84 & 6.62 & 353 \\
& $\mathrm{~K}$ & 35.4 & 3.36 & 5.96 & 360 \\
& $\mathrm{Rb}$ & 27.8 & 3.15 & 5.48 & 359 \\
& $\mathrm{Cs}^{\mathrm{a}}$ & 10.2 & 3.27 & 5.54 & 360 \\
\hline
\end{tabular}

${ }^{\mathrm{a}}$ Cesium picrate extractions were conducted using a different concentration. ${ }^{\mathrm{b}}$ Calculated from aqueous phase absorbance readings (see Experimental Section).

In almost every case, association constants for complexation of the alkali metal picrates were increased by lengthening of the spacer between the crown ether unit and central benzene ring in bis(15-crown-5) analogues 2, 7, and $\mathbf{8}$. Only the association constants of $\mathbf{5}$ with $\mathrm{Cs}^{+}$and $\mathbf{1 0}$ with $\mathrm{Rb}^{+}$showed decreases compared with $\mathbf{7}$ and $\mathbf{8}$. 
Extraction efficiencies of these hosts for $\mathrm{Li}^{+}$were again uniformly low. Association constants for $\mathrm{Na}^{+}$remain constant as the attachment sites for the two crown ether-containing substituents are varied from ortho to meta to para. Once again the $\lambda_{\max }$ values show that the ortho isomer (5) forms 2:1 complexes with $\mathrm{K}^{+}$and $\mathrm{Rb}^{+}$. The extraction complex for $\mathrm{Cs}^{+}$and $\mathbf{5}$ appears to have mixed stoichiometry.

Although some propensity for complexation of the larger metal ions is lost in going from ortho-isomer 5 to meta-isomer 9, the $\lambda_{\max }$ values reveal that the latter continues to form $2: 1$ complexes with $\mathrm{K}^{+}$and $\mathrm{Rb}^{+}$. The para-isomer 10 does not form 2:1 complexes with any of the alkali metal cations. Differences in the nature of $\mathrm{K}^{+}$and $\mathrm{Rb}^{+}$complexation by $\mathbf{5}$ and $\mathbf{9}$ versus $\mathbf{1 0}$ is responsible for the markedly enhanced affinities of $\mathbf{5}$ and $\mathbf{9}$ for these alkali metal cations, especially for $\mathrm{Rb}^{+}$(see Figure 2). Small, but steady, increases in association constants for $\mathrm{Cs}^{+}$ complexation in going from $\mathbf{5}$ to $\mathbf{9}$ to $\mathbf{1 0}$ may be due to easier formation of intermolecular complexes of the 2:1 type or could reflect enhanced interaction of this soft cation with the $\pi$ electron cloud of the benzene ring during complexation. ${ }^{20}$ However, preliminary ${ }^{1} \mathrm{H}$ NMR studies of 10 in $\mathrm{d}_{6}$-acetone showed no downfield shift of the aromatic protons upon addition of cesium nitrate to the sample, indicating little or no $\pi$-cloud interaction.

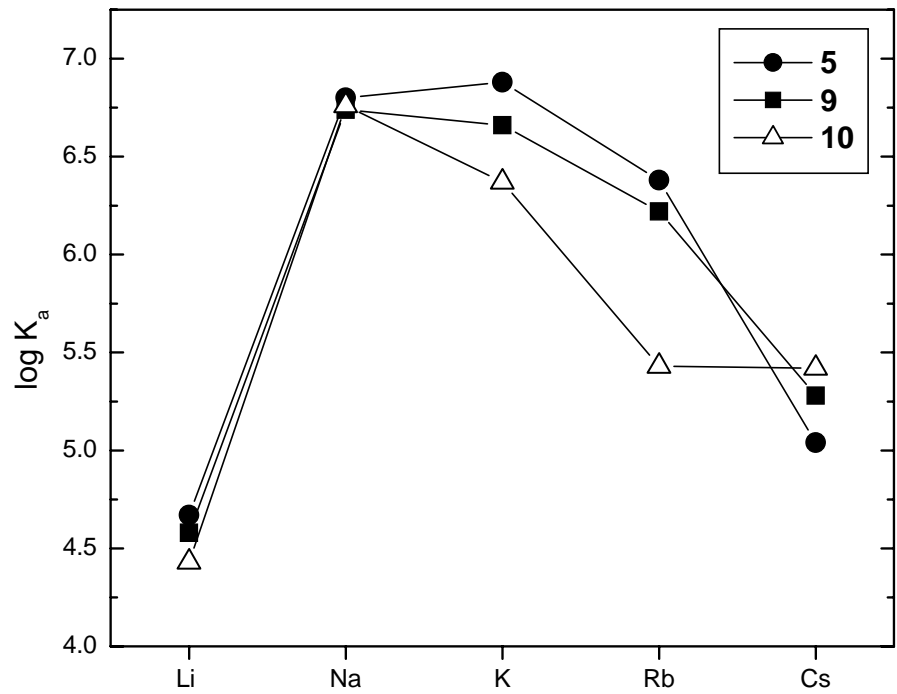

Figure 2. Association constants for complexation of alkali metal picrates by bis(15-crown-5) compounds 5, 9, and $\mathbf{1 0 .}$

\section{1-Methoxy-2,6-bis( $\alpha, \alpha^{\prime}$-oxymethyl-15-crown-5)xylene (11)}

Replacement of the hydrogen on the central benzene ring between the two crown ethercontaining substituents in meta-isomer 9 gives bis(15-crown-5) 11. Picrate extraction data and association constants $\left(\mathrm{K}_{\mathrm{a}}\right)$ for complexation of alkali metal picrates by $\mathbf{9}$ and $\mathbf{1 1}$ are given in Table 3 . From the $\lambda_{\max }$ values for alkali metal picrate extraction by $\mathbf{1 1}$, only $1: 1$ complexation is 
evident. In agreement, $\mathrm{Na}^{+}$, which provides the best match with the cavity size of a single $15-$ crown-5 unit, has the largest association constant. Association constants for complexation of alkali metal picrates decrease in the order $\mathrm{Na}^{+}>\mathrm{K}^{+}>\mathrm{Li}^{+}, \mathrm{Rb}^{+}, \mathrm{Cs}^{+}$.

\section{Bis(18-crown-6) hosts 3 and 6 and mono(18-crown-6) hosts 12 and 13 Bis(18-crown-6) hosts}

Picrate extraction data and association constants $\left(\mathrm{K}_{\mathrm{a}}\right)$ for complexation of alkali metal picrates by bis(crown ethers) 3 and $\mathbf{6}$ are presented in Table 4.

Table 4. Alkali metal picrate extraction from aqueous solution into deuteriochloroform by bis(18-crown-6) ligands 3 and $\mathbf{6}$

\begin{tabular}{cccccc}
\hline Ligand & $\mathrm{M}^{+}$ & Percent extraction & $\log \mathrm{K}_{\mathrm{ex}}$ & $\log \mathrm{K}_{\mathrm{a}}$ & $\lambda_{\max }(\mathrm{nm})$ \\
\hline $\mathbf{3}$ & $\mathrm{Li}$ & 3.2 & 1.87 & 4.72 & 380 \\
& $\mathrm{Na}$ & 24.2 & 3.04 & 5.79 & 366 \\
& $\mathrm{~K}$ & 95.2 & 6.04 & 8.85 & 366 \\
& $\mathrm{Rb}$ & 82.4 & 5.06 & 7.34 & 366 \\
& $\mathrm{Cs}^{\mathrm{a}}$ & 19.6 & 4.37 & 6.67 & 370 \\
\hline $\mathbf{6}$ & $\mathrm{Li}$ & 3.4 & 1.92 & 4.76 & 380 \\
& $\mathrm{Na}$ & 21.0 & 2.95 & 5.68 & 364 \\
& $\mathrm{~K}$ & 93.2 & 5.71 & 8.51 & 366 \\
& $\mathrm{Rb}$ & 83.8 & 5.08 & 7.42 & 365 \\
& $\mathrm{Cs}^{\mathrm{a}}$ & 19.0 & 4.34 & 6.62 & 370 \\
\hline
\end{tabular}

${ }^{\mathrm{a} C e s i u m ~ p i c r a t e ~ e x t r a c t i o n s ~ w e r e ~ c o n d u c t e d ~ u s i n g ~ a ~ d i f f e r e n t ~ c o n c e n t r a t i o n . ~}$

For the bis(18-crown-6) ligands $\mathbf{3}$ and $\mathbf{6}, \lambda_{\max }$ values for all of the alkali metal picrates except $\mathrm{Li}^{+}$are consistent with 1:1 complexes. In agreement, $\mathrm{K}^{+}$, which provides the best match with the cavity size of a single 18-crown-6 unit, has the largest association constant. Association constants for complexation of alkali metal picrates decrease in the order $\mathrm{K}^{+}>\mathrm{Rb}^{+}>\mathrm{Cs}^{+}>\mathrm{Na}^{+}>\mathrm{Li}^{+}$. Although the $\lambda_{\max }$ values for $\mathrm{Li}^{+}$might suggest 2:1 complexes, they are attributed instead to the ability of $\mathrm{Li}^{+}$to carry waters of solvation into its complexes with large ring crown ethers. ${ }^{21}$

\section{Comparison of bis(18-crown-6) hosts 3 and 6 with mono(18-crown-6) hosts 12 and 13} In the extraction studies of $\mathrm{K}^{+}$with bis(18-crown-6) compounds $\mathbf{3}$ and $\mathbf{6}$, the association constants were so high that it was necessary to conduct separate extractions at a host:guest ratio of 1:2 (ligand:alkali metal picrate). Extraction data and association constants for bis(18-crown-6) ligands 3 and $\mathbf{6}$ determined under these conditions are compared with those for mono(18-crown6) model compounds $\mathbf{1 2}$ and $\mathbf{1 3}$ obtained with the customary 1:1 host:guest ratio are presented in Table 5. The differing ratios correct for the fact that each bis(crown ether) ligand provides two 18-crown-6 units, while each mono(crown ether) molecule has a single 18-crown-6 ring. 
Comparison of the data for bis(crown ether) 3 with mono(crown ether) 12 and of bis(crown ether) 6 with mono(crown ether) 13 reveals no substantial differences between the extraction data and association constants obtained under these conditions. This is consistent with formation of only 1:1 complexes (one crown ether unit per metal ion) and is supported by the $\lambda_{\max }$ values for the four ligands.

Table 5. Alkali metal picrate extraction from aqueous solution into deuteriochloroform by bis(18-crown-6) ligands $\mathbf{3}$ and $\mathbf{6}$ and mono(18-crown-6) ligands $\mathbf{1 2}$ and $\mathbf{1 3}$

\begin{tabular}{cccccc}
\hline Ligand & $\mathrm{M}^{+}$ & Percent extraction & $\log \mathrm{K}_{\mathrm{ex}}$ & $\log \mathrm{K}_{\mathrm{a}}$ & $\lambda_{\max }(\mathrm{nm})$ \\
\hline $\mathbf{3}^{\mathrm{a}}$ & $\mathrm{Na}$ & 32.7 & 3.10 & 5.84 & 359 \\
& $\mathrm{~K}$ & 85.7 & 5.60 & 8.12 & 367 \\
\hline $\mathbf{6}^{\mathrm{a}}$ & $\mathrm{Na}$ & 25.8 & 2.87 & 5.60 & 359 \\
& $\mathrm{~K}$ & 69.6 & 4.63 & 7.03 & 367 \\
\hline $\mathbf{1 2}^{\mathrm{b}}$ & $\mathrm{Na}$ & 24.9 & 2.81 & 5.57 & 351 \\
& $\mathrm{~K}$ & 81.5 & 5.09 & 7.73 & 365 \\
& $\mathrm{Rb}$ & 63.4 & 4.78 & 7.10 & 361 \\
\hline $\mathbf{1 3}^{\mathrm{b}}$ & $\mathrm{Na}$ & 24.3 & 2.80 & 5.56 & 358 \\
& $\mathrm{~K}$ & 66.8 & 4.27 & 6.90 & 367 \\
& $\mathrm{Rb}$ & 64.4 & 4.83 & 7.14 & 362 \\
\hline
\end{tabular}

${ }^{a}$ Extractions performed with $15 \mathrm{mM}$ bis(crown ether) and $30 \mathrm{mM}$ metal picrate. ${ }^{b}$ Extractions performed with $30 \mathrm{mM}$ crown ether and $30 \mathrm{mM}$ metal picrate.

\section{Summary}

The new biscrown ethers 1-10 provide a series with systematic structural variations of the ring size, the positioning of the two crown ether rings on a central benzene unit and the length of the tether that connects each crown ether unit to the benzene ring. Alkali metal picrate extraction results reveal that these structural variations affect the efficiency with which a particular metal ion is extracted, as well as its interaction with one or both crown ether rings.

In $\mathbf{1}$ and $\mathbf{4}$, the two 12-crown-4 rings are attached ortho on the benzene ring by $-\mathrm{OCH}_{2}$ - and $-\mathrm{CH}_{2} \mathrm{OCH}_{2}$ - units, respectively. Compared with the other biscrown ether compounds, $\mathbf{1}$ and $\mathbf{4}$ are only weak extractants for alkali metal cations. Both ligands give strongest complexation of $\mathrm{Na}^{+}$ with formation of mixed complexes in which the metal ion interacts with one and both polyether rings. For $\mathrm{K}^{+}$and $\mathrm{Rb}^{+}$, both crown ether units interact with the complexed metal ion.

The most complete structural effect study includes the five bis(15-crown-5) compounds $\mathbf{2 ,} \mathbf{5}$, and 7-9. In the alkali metal picrate extractions, all of these ligands are weak extractants of $\mathrm{Li}^{+}$ and $\mathrm{Cs}^{+}$. For 2, 7, and $\mathbf{8}$, the two crown ether rings are positioned ortho, meta and para, respectively, with $-\mathrm{OCH}_{\mathrm{s}}$ - tethers between the 15 -crown-5 rings and the central benzene ring. The association constant orders are $\mathrm{K}^{+}>\mathrm{Na}^{+}>\mathrm{Rb}^{+}$for $\mathbf{2}$ and $\mathrm{Na}^{+}>\mathrm{K}^{+}>\mathrm{Rb}^{+}$for $\mathbf{7}$ and $\mathbf{8}$. This differing ordering for ortho-substituted ligand 2 results from interaction of $\mathrm{K}^{+}$with both crown 
ether rings; whereas the complexed metal ion interacts with only one cyclic polyether unit in 7 and 8. With alteration of the tether to $-\mathrm{CH}_{2} \mathrm{OCH}_{2-}$, the extraction selectivity is $\mathrm{K}^{+}, \mathrm{Na}^{+}>\mathrm{Rb}^{+}$for 5 and $\mathbf{9}$, but $\mathrm{Na}^{+}>\mathrm{K}^{+}>\mathrm{Rb}^{+}$for $\mathbf{1 0}$ with $\mathrm{K}^{+}$complexed by two crown ether rings in $\mathbf{5}$ and $\mathbf{9}$, but only one in 10. For the two ortho-substituted bis(18-crown-6) compounds 3 and $\mathbf{6}$, the stability constant order is $\mathrm{K}^{+}>\mathrm{Rb}^{+}>\mathrm{Na}^{+}>\mathrm{Cs}^{+}>\mathrm{Li}^{+}$and only interactions of the complexed metal ion with a single crown ether unit are evident.

\section{Experimental Section}

General Procedures. IR spectra were obtained on neat samples with a Nicolet MX-S spectrometer and are recorded in wavenumbers. ${ }^{1} \mathrm{H}$ NMR spectra were recorded with a Varian EM 360 spectrometer in $\mathrm{CDCl}_{3}$ and chemical shifts are reported in parts per million $(\delta)$ downfield from TMS. UV-visible spectra were recorded with a Perkin-Elmer Lambda 5 spectrophotometer. Elemental analyses were performed by Galbraith Laboratories, Inc. of Knoxville, Tennessee. Unless specified otherwise, reagent-grade reactants and solvents were obtained from commercial suppliers and were used as received. THF was purified by distillation from $\mathrm{LiAlH}_{4}$ under nitrogen. Hydroxymethyl-12-crown-4, hydroxymethyl-15-crown-5, and hydroxymethyl-18-crown- 6 and their tosylates were prepared by literature methods. ${ }^{22-25}$ Ligand 13 was prepared by a reported method. ${ }^{23}$ The 2,6-bis(bromomethyl)anisole was obtained from 2,6-dimethylanisole by bromination with $\mathrm{N}$-bromosuccinimide.

\section{General procedure for synthesis of bis(oxymethylcrown)benzenes 1-3, 7, and 8}

Under nitrogen, $\mathrm{KH}$ (22\% suspension in mineral oil, $11.0 \mathrm{mmol})$ was suspended in $8 \mathrm{~mL}$ of THF. (In some cases $\mathrm{NaH}$ was used as the base.) To this mixture, a solution of the appropriate dihydroxybenzene $(3.1 \mathrm{mmol})$ in THF $(10 \mathrm{~mL})$ was added dropwise at room temperature. After 1 $\mathrm{h}$, a solution of the appropriate (tosyloxymethyl)crown ether $(6.2 \mathrm{mmol})$ in THF $(10 \mathrm{~mL})$ was added and the mixture was refluxed for $48 \mathrm{~h}$. The solvent was evaporated in vacuo. Water $(30 \mathrm{~mL})$ was added to the residue and the mixture was extracted with $\mathrm{CH}_{2} \mathrm{Cl}_{2}(2 \mathrm{X} 20 \mathrm{~mL})$. The combined extracts were dried $\left(\mathrm{MgSO}_{4}\right)$ and the solvent was evaporated in vacuo to give the crude product that was purified by column chromatography on neutral alumina.

1,2-Bis(oxymethyl-12-crown-4)benzene (1). Coupling of catechol $(0.34 \mathrm{~g}, 3.1 \mathrm{mmol})$ and tosyloxymethyl-12-crown-4 (2.24 g, $6.2 \mathrm{mmol})$ was conducted by the general procedure. After chromatography with EtOAc as eluent, $1.05 \mathrm{~g}(70 \%)$ of 1 was obtained as a very hygroscopic, pale yellow oil: IR (neat): $1126(\mathrm{C}-\mathrm{O}) \mathrm{cm}^{-1} .{ }^{1} \mathrm{H}$ NMR $\left(\mathrm{CDCl}_{3}\right): \delta 3.50-4.20(\mathrm{~m}, 34 \mathrm{H}), 6.88(\mathrm{~s}$, $4 \mathrm{H})$. Analysis calculated for $\mathrm{C}_{24} \mathrm{H}_{38} \mathrm{O}_{10}$ : C, 59.24; $\mathrm{H}, 7.87$. Found: $\mathrm{C}, 59.05 ; \mathrm{H}, 7.77$.

1,2-Bis(oxymethyl-15-crown-5)benzene (2). On a reduced scale, catechol (0.28 g, $2.5 \mathrm{mmol})$ was reacted with tosyloxymethyl-15-crown-5 $(2.02 \mathrm{~g}, 5.0 \mathrm{mmol})$ under conditions of the general procedure. Chromatography with EtOAc-MeOH (15:1) as eluent gave $2(1.17 \mathrm{~g}, 81 \%)$ as an extremely hygroscopic, colorless liquid. IR (neat): $1126(\mathrm{C}-\mathrm{O}) \mathrm{cm}^{-1} .{ }^{1} \mathrm{H}$ NMR $\left(\mathrm{CDCl}_{3}\right): \delta 3.52-$ 
$4.32(\mathrm{~s}+\mathrm{m}, 42 \mathrm{H}), 6.88(\mathrm{~s}, 4 \mathrm{H})$. Analysis calculated for $\mathrm{C}_{28} \mathrm{H}_{46} \mathrm{O}: \mathrm{C}, 58.52 ; \mathrm{H}, 8.07$. Found: C, $58.62 ; \mathrm{H}, 8.12$.

1,2-Bis(oxymethyl-18-crown-6)benzene (3). On a reduced scale, catechol (0.27 g, $2.4 \mathrm{mmol})$ was coupled with tosyloxymethyl-18-crown-6 (2.19 g, $4.9 \mathrm{mmol})$ using $\mathrm{NaH}(0.26 \mathrm{~g}$ of 50\% suspension in mineral oil, $5.4 \mathrm{mmol}$, with mineral oil removed by washing with pentane). Chromatography with EtOAc-MeOH (20:1) as eluent gave 3 (1.05 g, 65\%) as an extremely hygroscopic, colorless oil. IR (neat): $1128(\mathrm{C}-\mathrm{O}) \mathrm{cm}^{-1} .{ }^{1} \mathrm{H} \mathrm{NMR}\left(\mathrm{CDCl}_{3}\right): \delta 3.50-4.32(\mathrm{~s}+\mathrm{m}$, $50 \mathrm{H}), 6.89$ (s, 4H). Analysis calculated for $\mathrm{C}_{32} \mathrm{H}_{54} \mathrm{O}_{14}$ : C, 57.99; H, 8.21. Found: C, 57.83; H, 8.23 .

1,3 Bis(oxymethyl-15-crown-5)benzene (7). Under the same conditions that were used for the synthesis of 2, but replacing catechol with resorcinol, tosyloxymethyl-15-crown-5 (2.02 g, 5.0 $\mathrm{mmol})$ and resorcinol $(0.275 \mathrm{~g}, 2.5 \mathrm{mmol})$ were combined. After chromatography of the crude product with EtOAc-MeOH (40:1) as eluent, 7 (1.17 g, 81\%) was obtained as a colorless, viscous, hygroscopic oil. IR (neat): $1130(\mathrm{C}-\mathrm{O}) \mathrm{cm}^{-1} .{ }^{1} 1 \mathrm{H} \mathrm{NMR}\left(\mathrm{CDCl}_{3}\right): \delta 3.50-4.32(\mathrm{~m}, 42 \mathrm{H})$, 6.31-6.65 (m, 3H); 6.90-7.32 (m, $1 \mathrm{H})$. Analysis calculated for $\mathrm{C}_{28} \mathrm{H}_{46} \mathrm{O}_{12}$ : C, 58.52; $\mathrm{H}, 8.07$. Found: C. 58.54; H, 8.12.

1,4-Bis(oxymethyl-15-crown-5)benzene (8). Hydroquinone $(0.275 \mathrm{~g}, 2.5 \mathrm{mmol})$ and tosyloxymethyl-15-crown-5 $(2.02 \mathrm{~g}, 5.0 \mathrm{mmol})$ were combined under the same conditions as described above. Chromatography with EtOAc-MeOH (40:1) as eluent gave $1.25 \mathrm{~g}(85 \%)$ of 8 as a hygroscopic, colorless oil. IR (neat): $1126(\mathrm{C}-\mathrm{O}) \mathrm{cm}^{-1} .{ }^{1} \mathrm{H}$ NMR $\left(\mathrm{CDCl}_{3}\right): \delta 3.45-4.11(\mathrm{~m}$, $42 \mathrm{H}), 6.80(\mathrm{~s}, 4 \mathrm{H})$. Analysis calculated for $\mathrm{C}_{28} \mathrm{H}_{46} \mathrm{O}_{12}$ : C, 58.52; H, 8.07. Found: C, 58.31; H, 8.12 .

General procedure for the synthesis of $\boldsymbol{\alpha , \alpha}$-bis(oxymethylcrown)xylenes 4-6, 9, and $10 \mathrm{NaH}$ (50\% in mineral oil, $0.21 \mathrm{~g}, 4.4 \mathrm{mmol}$ ) was washed with pentane under nitrogen and suspended in THF $(5 \mathrm{~mL})$. A solution of the (hydroxymethyl)crown ether $(4.0 \mathrm{mmol})$ in THF $(2 \mathrm{~mL})$ was added dropwise. After stirring at room temperature for $1 \mathrm{~h}$, a solution of the appropriate dibromide $(2.0 \mathrm{mmol})$ in THF was added and the mixture was refluxed overnight. The solvent was evaporated in vacuo and the crude product was chromatographed on alumina.

$\boldsymbol{\alpha}, \boldsymbol{\alpha}^{\prime}$-Bis(oxymethyl-12-crown-4)-ortho-xylene (4). The reaction of hydroxymethyl-12-crown-4 $(0.82 \mathrm{~g}, 4.0 \mathrm{mmol})$ with $\alpha, \alpha$-dibromo-o-xylene $(0.52 \mathrm{~g}, 2.0 \mathrm{mmol})$ was conducted using the general procedure. Chromatography with EtOAc and then EtOAc-MeOH (40:1) as eluents gave $4(0.75 \mathrm{~g}, 73 \%)$ as an extremely hygroscopic, pale yellow oil. IR (neat): 1126, $1095(\mathrm{C}-\mathrm{O}) \mathrm{cm}^{-1}$. ${ }^{1} \mathrm{H}$ NMR $\left(\mathrm{CDCl}_{3}\right): \delta$ 3.35-4.05 $(\mathrm{s}+\mathrm{m}, 34 \mathrm{H}), 4.59(\mathrm{~s}, 4 \mathrm{H}), 7.32(\mathrm{~s}, 4 \mathrm{H})$. Analysis calculated for $\mathrm{C}_{26} \mathrm{H}_{42} \mathrm{O}_{10} \bullet 0.5 \mathrm{H}_{2} \mathrm{O}: \mathrm{C}, 59.64, \mathrm{H} 8.28$; Found: C, 59.76; $\mathrm{H}, 8.03$.

$\boldsymbol{\alpha}, \boldsymbol{\alpha}^{\prime}$-Bis(oxymethyl-15-crown-5)-ortho-xylene (5). On a larger scale, hydroxymethyl-15-crown5 (1.25 g, $5.0 \mathrm{mmol})$ was reacted with $\alpha, \alpha$-dibromo-o-xylene $(0.66 \mathrm{~g}, 2.5 \mathrm{mmol})$ using the general procedure. After chromatography with EtOAc and then EtOAc-MeOH (20:1) as eluents, $1.26 \mathrm{~g} \mathrm{(71 \% )} \mathrm{of} 5$ was obtained as a viscous, hygroscopic, pale yellow oil. IR (neat): 1124 (C-O) 
$\mathrm{cm}^{-1} .{ }^{1} \mathrm{H}$ NMR $\left(\mathrm{CDCl}_{3}\right): \delta$ 3.35-4.02 $(\mathrm{s}+\mathrm{m}, 42 \mathrm{H}), 4.60(\mathrm{~s}, 4 \mathrm{H}), 7.33(\mathrm{br} \mathrm{s}, 4 \mathrm{H})$. Analysis calculated for $\mathrm{C}_{30} \mathrm{H}_{50} \mathrm{O}_{12}$ : C, 59.78; H, 8.36. Found: C, 59.72; H, 8.47.

$\boldsymbol{\alpha}, \boldsymbol{\alpha}^{\prime}$-Bis(oxymethyl-18-crown-6)-ortho-xylene (6). On a reduced scale, hydroxymethyl-18crown-6 (0.64 g, $2.2 \mathrm{mmol})$ was combined with $\alpha, \alpha^{\prime}$-dibromo-o-xylene $(0.25 \mathrm{~g}, 0.95 \mathrm{mmol})$ using the general procedure. Chromatography with EtOAc and then EtOAc-MeOH (40:1) as eluents gave $6(0.46 \mathrm{~g}, 70 \%)$ as a viscous, very hygroscopic, pale yellow oil. IR (neat): 1116 (CO) $\mathrm{cm}^{-1} .{ }^{1} \mathrm{H} \mathrm{NMR}\left(\mathrm{CDCl}_{3}\right): \delta 3.65(\mathrm{br} \mathrm{s}, 50 \mathrm{H}), 4.60(\mathrm{~s}, 4 \mathrm{H}), 7.32(\mathrm{~s}, 4 \mathrm{H})$. Analysis calculated for $\mathrm{C}_{34} \mathrm{H}_{58} \mathrm{O}_{14} \bullet 0.5 \mathrm{H}_{2} \mathrm{O}: \mathrm{C}, 58.35 ; \mathrm{H}, 8.50$. Found: $\mathrm{C}, 58.48 ; \mathrm{H}, 8.35$.

$\boldsymbol{\alpha}, \boldsymbol{\alpha}^{\prime}$-Bis(oxymethyl-15-crown-5)-meta-xylene (9). On an increased scale, hydroxymethyl-15crown-5 (1.25 g, $5.0 \mathrm{mmol})$ was reacted with $\alpha, \alpha^{\prime}$-dibromo-m-xylene (0.66 g, $\left.2.5 \mathrm{mmol}\right)$ using the general procedure. Chromatography with EtOAc and then EtOAc-MeOH (20:1) as eluents gave $9(0.85 \mathrm{~g}, 56 \%)$ as a viscous, pale yellow oil. IR (neat): 1124 (C-O) $\mathrm{cm}^{-1}$. ${ }^{1} \mathrm{H}$ NMR $\left(\mathrm{CDCl}_{3}\right): \delta 3.65($ br s, $42 \mathrm{H}), 4.52(\mathrm{~s}, 4 \mathrm{H}), 7.23(\mathrm{~s}, 4 \mathrm{H})$. Analysis calculated for $\mathrm{C}_{32} \mathrm{H}_{50} \mathrm{O}_{12}$ : $\mathrm{C}$, 59.78; H, 8.36. Found: C, 59.63; H, 8.42.

$\boldsymbol{\alpha}, \boldsymbol{\alpha}^{\prime}$-Bis(oxymethyl-15-crown-5)-para-xylene (10). With the general procedure, hydroxymethyl-15-crown-5 (1.25 g, $5.0 \mathrm{mmol})$ and $\alpha, \alpha^{\prime}$-dibromo- $p$-xylene (0.66 g, $\left.2.5 \mathrm{mmol}\right)$ were combined. Chromatography with EtOAc and then EtOAc-MeOH (40:1) as eluents gave $0.75 \mathrm{~g}(50 \%)$ of 10 as a hygroscopic, colorless, heavy oil. IR (neat): $1126(\mathrm{C}-\mathrm{O}) \mathrm{cm}^{-1} .{ }^{1} \mathrm{H}$ NMR $\left(\mathrm{CDCl}_{3}\right): \delta$ 3.30-4.00 (m, 42H), $4.53(\mathrm{~s}, 4 \mathrm{H}), 7.28(\mathrm{~s}, 4 \mathrm{H})$. Analysis calculated for $\mathrm{C}_{30} \mathrm{H}_{50} \mathrm{O}_{12} \times \mathrm{H}_{2} \mathrm{O}: \mathrm{C}, 58.90 ; \mathrm{H}, 8.40$. Found: C, 58.54; H, 8.41.

2-Methoxy-1,3-bis-( $\boldsymbol{\alpha}, \boldsymbol{\alpha}^{\prime}$-oxymethyl-15-crown-5)-meta-xylene (11). Under nitrogen, $\mathrm{NaH}$ (50\% suspension in mineral oil; $0.60 \mathrm{~g}, 12.5 \mathrm{mmol}$ ) was washed with pentane and suspended in THF (10 mL). A solution of hydroxymethyl-15-crown-5 $(2.50 \mathrm{~g}, 10.0 \mathrm{mmol})$ in THF $(10 \mathrm{ml})$ was added dropwise and the mixture was stirred for $1 \mathrm{~h}$ at room temperature. A solution of 2,6-bis(bromomethyl)anisole $(1.47 \mathrm{~g}, 5.0 \mathrm{mmol})$ in THF $(5 \mathrm{~mL})$ was added and the resulting mixture was refluxed for $36 \mathrm{~h}$. The solvent was removed in vacuo and the residue was chromatographed on alumina with EtOAc and then EtOAc-MeOH (40:1) as eluents to give 11 $(1.68 \mathrm{~g}, 53 \%)$ as a colorless, viscous oil. IR (neat): $1128(\mathrm{C}-\mathrm{O}) \mathrm{cm}^{-1} .{ }^{1} \mathrm{H} \mathrm{NMR}\left(\mathrm{CDCl}_{3}\right): \delta$ 3.30-4.00 (m, 45H), $4.58(\mathrm{~s}, 4 \mathrm{H}), 6.90-7.50(\mathrm{~m}, 3 \mathrm{H})$. Analysis calculated for $\mathrm{C}_{31} \mathrm{H}_{52} \mathrm{O}_{13}$ : C, 58.85; H, 8.28. Found: C, 58.66; H, 8.50.

Phenoxymethyl-18-crown-6 (12). NaH (50\% suspension in mineral oil, $0.09 \mathrm{~g}, 1.9 \mathrm{mmol}$ ) was washed with pentane under nitrogen and suspended in THF $(10 \mathrm{~mL})$. A solution of phenol $(0.17 \mathrm{~g}, 1.8 \mathrm{mmol})$ in THF $(20 \mathrm{~mL})$ was added slowly. After stirring for $1 \mathrm{~h}$ at room temperature, a solution of tosyloxymethyl-18-crown-6 $(0.79 \mathrm{~g}, 1.8 \mathrm{mmol})$ in THF $(20 \mathrm{~mL})$ was added and the mixture was refluxed for $48 \mathrm{~h}$. The solvent was removed in vacuo and the residue was chromatographed on alumina with $\mathrm{CHCl}_{3}$-EtOH (50:3) as eluent to give $12(0.64 \mathrm{~g}, 96 \%)$ as a pale yellow, viscous liquid. IR (neat): $1122(\mathrm{C}-\mathrm{O}) \mathrm{cm}^{-1} .{ }^{1} \mathrm{H} \mathrm{NMR}\left(\mathrm{CDCl}_{3}\right): \delta 3.50-4.15(\mathrm{~m}, 25 \mathrm{H})$; 6.70-7.40 (m, 5H). Analysis calculated for $\mathrm{C}_{19} \mathrm{H}_{30} \mathrm{O}_{7}$ : C, 61.60; H, 8.16. Found: C, 61.46; H, 8.36 . 
Preparation of alkali metal picrates. The alkali metal picrates were prepared by dissolving picric acid in a minimum amount of boiling distilled water and slowly adding a stoichiometric amount of the alkali metal carbonate. The solution was cooled to room temperature and placed in an ice bath to facilitate crystallization. The precipitate was filtered and recrystallized once from distilled water. After filtration and extensive air drying, the salt was carefully heated to dryness in a vacuum oven at $100^{\circ} \mathrm{C}$ for $3 \mathrm{~h}$. (Although we have never experienced any difficulty with this step, caution must be exercised in drying any metal picrate salt. Heating should not exceed $100^{\circ} \mathrm{C}$ and the salt should be allowed to cool to room temperature under vacuum before handling.) The anhydrous metal picrate was stored in the dark in a vacuum desiccator.

Procedure for picrate extractions. Except where noted (Table II), extractions of alkali metal picrates with bis(crown ether) hosts were performed by placing $0.50 \mathrm{~mL}$ of a $15 \mathrm{mM}$ solution of the metal picrate in deionized water and $0.50 \mathrm{~mL}$ of a $15 \mathrm{mM}$ solution of the bis(crown ether) in deuteriochloroform into a $15-\mathrm{mL}$ centrifuge tube and mixing the solutions on a vortex mixer for $60 \mathrm{sec}$. Five samples were prepared for each picrate extraction experiment. The tubes were centrifuged for $10 \mathrm{~min}$ and then allowed to stand for $10 \mathrm{~min}$ to assure complete separation of the layers. Aliquots were taken from each phase of the sample in the tube and the concentration of metal picrate in each phase was determined by UV-visible absorbance scanning from $550 \mathrm{~nm}$ to $320 \mathrm{~nm}$. In some cases, the organic phase concentration was determined by difference from the aqueous phase readings before and after extraction because of turbidity or formation of complexes insoluble in THF. The extraction constants $\left(\mathrm{K}_{\mathrm{ex}}\right)^{14}$ and association constants $\left(\mathrm{K}_{\mathrm{a}}\right)^{15}$ were calculated according to previously developed methods. Standard deviations from the analysis of the five samples were less than $10 \%$ of the $\mathrm{K}_{\mathrm{ex}}$ and $\mathrm{K}_{\mathrm{a}}$ values. All extractions of cesium involved $5 \mathrm{mM}$ cesium picrate and $15 \mathrm{mM}$ bis(crown ether) due to the lower solubility of cesium picrate.

\section{Acknowledgments}

This research was support by The Robert A. Welch Foundation (Grant D-0775 to RAB).

\section{References}

1. Pedersen, C. J. J. Am. Chem. Soc. 1970, 92, 386.

2. Mallinson, P. R.; Truter, M. R. J. Chem. Soc., Perkin Trans. 2 1972, 1818.

3. van Remoorter, F. P.; Boer, F. P. Inorg. Chem. 1974, 13, 2071.

4. Cram, D. J.; Cram, J. M. Science 1974, 183, 803.

5. Wong, K. H.; Bourgoin, M.; Dale, J. J. Chem. Soc., Chem. Commun. 1974, 715.

6. An, H.; Bradshaw, J. S.; Izatt, R. M.; Yan, Z. Chem. Rev. 1994, 94, 939. 
7. Kimura, K.; Tamura, H.; Shono, T. J. Electroanal. Chem. 1979, 105, 335.

8. Kimura, K.; Maeda, T.; Shono, T. Anal. Lett. 1978, A11, 821.

9. Kimura, K.; Tamura, H.; Tsuchida, T.; Shono, T. Chem. Lett. 1979, 611.

10. Kimura, K.; Tamura, H.; Shono, T. J. Chem. Soc., Chem. Commun. 1983, 492.

11. Elben, U.; Vögtle, F. J. Chem. Res. 1978, 3791.

12. Calverly, M. J.; Dale, J. J. Chem. Soc., Chem. Commun. 1981, 684.

13. Cho, Y. H.; Rha, S. G,; Chang, S. K.; Cho, K.; Kim, H. J. Inclusion Phenom. Molec. Recognit. Chem. 1988, 31, 119.

14. Sadakane, A.; Iwachido, T.; Toei, K. Bull. Chem. Soc. Jpn. 1975, 48, 60.

15. Moore, S. S.; Tarnowski, T. L., Newcomb, M.; Cram, D. J. J. Am. Chem. Soc. 1977, 99, 6398.

16. Groth, P. Acta Chem. Scand. 1981, A35, 460.

17. Groth, P. Acta Chem. Scand. 1981, A35, 463.

18. Anet, F. A. L.; Krane, J.; Dale, J.; Deasvatn, K.; Kristiansen, P. O. Acta Chem. Scand. 1975, A27, 3395.

19. Hope, H.; Olmstead, M. M.; Power, P. O.; Xu, X. J. Am. Chem. Soc. 1984, 106, 819.

20. Kawasima, N.; Kawasima, T.; Otsibp. T.; Misumi, S. Tetrahedron Lett. 1978, 50, 5025.

21. Czugler, M. J. Chem. Soc., Chem. Commun. 1981, 472.

22. Ikeda, I.; Yamamura, S.; Nakatsuji, Y,; Okahara, M. J. Org. Chem. 1980, 45, 5355.

23. Czech, B. Tetrahedron Lett. 1980, 21, 4197.

24. Czech, B.; Son, B.; Bartsch, R. A. Tetrahedron Lett. 1983, 24, 2923.

25. Czech, B. P.; Czech, A.; Son, B.; Lee, H. K.; Bartsch, R. A. J. Heterocyclic Chem. 1986, 23, 465. 